\title{
A INSERÇÃO DOS TRABALHADORES MAIS ESCOLARIZADOS NO MERCADO DE TRABALHO BRASILEIRO: UMA ANÁLISE DE GÊNERO
}

\author{
THE INCLUSION OF WORKERS WITH HIGHER EDUCATIONS IN THE BRAZILIAN LABOR MARKET: \\ A GENDER ANALYSIS
}

Moema de Castro Guedes ${ }^{1}$

Resumo o presente artigo analisa, desde a perspectiva de gênero, o tipo de inserção laboral da população de nível universitário nos últimos trinta anos no século XX. Para tanto, em um primeiro momento traça as mudanças mais amplas assistidas no mundo do trabalho neste período a partir de um diálogo com a literatura de referência. Em seguida, a partir da base de dados dos censos demográficos do Instituto Brasileiro de Geografia e Estatística de 1970 e 2000, compara distintos padrões e tendências de algumas variáveis relativas ao mercado de trabalho na população feminina e masculina. Esse enfoque discute em que medida as dinâmicas assistidas neste segmento também reproduzem uma divisão sexual do trabalho. Os principais resultados encontrados mostram que já nos anos 1970 a maioria das mulheres deste grupo trabalhava em tempo integral. Essa tendência se acentua nos trinta anos em questão, e nas demais variáveis observam-se tendências cada vez mais próximas às masculinas. No entanto, a permanência da segmentação ocupacional feminina e dos altos diferenciais salariais aponta para uma desconstrução ainda lenta dos constrangimentos que cercam a presença destas mulheres no mundo do trabalho.

Palavras-chave relações de gênero; mercado de trabalho; mulheres de nível universitário.
Abstract This article examines, from a gender perspective, the type of employability the population holding higher education degrees had over the last thirty years of the twentieth century. To achieve its goals, it first outlines the broader changes witnessed in the work market in this period based on a dialogue with the literature of reference. Then, based on the Brazilian Institute of Geography and Statistics' database of census figures of 1970 and 2000, it compares different patterns and trends of some variables regarding the labor market among men and women. This approach discusses the extent to which the dynamics seen in this segment also play out a gender division of labor. The main results show that already in the 1970s most women in this group worked full time. This trend accentuated in the thirty years in question, and in the other variables trends increasingly closer to those seen among men were also noticeable. However, the persistence of female occupational segmentation and the major wage differentials still point to a gradual deconstruction of the constraints surrounding the presence of these women in the workplace.

Keywords gender relations; labor market; women with higher education degrees. 
Introdução

A mulher se confunde com seu sexo e se reduz a ele, que marca sua função na família e seu lugar na sociedade (Michelle Perrot, 2007).

As particularidades que envolvem o tipo de participação feminina no mercado de trabalho entre o segmento da população que tem um curso universitário completo são diversas e algumas delas já foram mapeadas em minha dissertação de mestrado (Guedes, 2004). Ali, o tipo de análise desenvolvida seguiu duas direções comparativas: por um lado, em relação ao corpo mais amplo de mulheres trabalhadoras e, por outro, aos homens do mesmo estrato educacional, ou seja, as desigualdades de gênero no mercado de trabalho.

A partir das questões mapeadas naquele campo - sumarizadas brevemente a seguir -, este artigo indaga em que medida o tradicional conceito de divisão sexual do trabalho poderia ser utilizado para explicar as dinâmicas encontradas no segmento de trabalhadores de nível universitário. Para tanto, pretende-se em um primeiro momento analisar as mudanças mais amplas assistidas no mundo do trabalho nos últimos anos do século XX. Em seguida, através do cruzamento de dados dos censos demográficos de 1970 e 2000, do Instituto Brasileiro de Geografia e Estatística (IBGE), comparam-se os estratos de horas semanais trabalhadas e salários de homens e mulheres de nível universitário, a fim de evidenciar a expansão, entre o contingente feminino, das trabalhadoras full time que passam a ocupar os postos mais altos da pirâmide salarial. Esse processo refletiria importantes mudanças no mundo do trabalho e, particularmente, uma realidade que cada vez mais coloca em xeque a figura masculina como o 'provedor natural' da família.

\section{Antecedentes: inserção laboral e diferenças salariais}

Os principais resultados encontrados pela dissertação de mestrado As mulheres de formação universitária: a reversão da desigualdade de gênero e seus reflexos no mercado de trabalho (Brasil: 1970-2000) (Guedes, 2004) relacionam-se, por um lado, às especificidades do tipo de inserção laboral das mulheres do segmento de nível universitário em comparação com outros estratos educacionais. Em um outro sentido, foram explorados os diferenciais salariais entre homens e mulheres deste grupo ao longo do tempo e através de grupos etários e carreiras específicas. Todas as análises tiveram como base de dados os censos demográficos de 1970 a 2000. 
Em linhas gerais, a análise comparativa do grupo em questão, em relação aos demais estratos educacionais da população feminina, mostrou as seguintes dimensões: o grupo com nível universitário é o que apresenta as maiores e mais constantes (ao longo do ciclo produtivo de vida) taxas de participação laboral. No entanto, é neste grupo mais escolarizado que se observam maiores e mais constantes desigualdades salariais por sexo. Essa comparabilidade entre censos e distintos perfis de trabalhadores foi possível graças à criação da variável 'salário mínimo por hora de trabalho' .

No que diz respeito aos enfoques deste expressivo deferencial salarial por sexo na população com nível universitário, verificamos que na população jovem, em início de carreira, as diferenças salariais entre homens e mulheres era mais reduzida, ganhando relevância à medida que os trabalhadores envelheciam e tinham uma progressão na profissão. A área na qual havia sido cursada a graduação também apareceu como um elemento importante de análise, pois as carreiras tipicamente masculinas ${ }^{2}$ apresentavam um diferencial salarial por sexo maior que aquelas nas quais as mulheres representavam a maioria do contingente de formados.

Esses dados mostram uma relação direta entre escolarização e participação feminina no mercado de trabalho - dimensão que reitera os achados de outros estudos como o de Soares e Isaki (2002). Além disso, as relações observadas na população feminina sugerem que a articulação entre investimento em qualificação e melhores postos de trabalho não é tão direta quanto costumam supor teorias econômicas como a do Capital Humano. Nesta direção, o olhar sobre este contingente populacional mais elitizado pode ser tomado como um locus privilegiado para a análise das desigualdades tanto nas identidades de gênero e das relações de poder que permeiam esse campo quanto no mundo do trabalho por meio de enfoques menos privilegiados pela teoria econômica tradicional.

\section{O lugar da trabalhadora mais qualificada no final do século XX no Brasil}

O intenso processo de inserção laboral da população feminina como um todo vem trazendo à tona, a partir do final do século XX, duas questões importantes. Embora as mulheres de nível universitário já se defrontassem com elas em 1970, recentemente ambas vêm adquirindo mais relevância na sociedade brasileira. A primeira é o fato de que as responsabilidades familiares não constituem um empecilho para a participação das mulheres no mercado de trabalho. Diversos trabalhos mostram que os principais incrementos da taxa total de participação laboral das mulheres nos últimos anos é resultado do grande aumento da inserção do grupo de mulheres casadas e com filhos. 
A segunda é a constatação de que, uma vez no mercado de trabalho, arcando com as despesas da casa de forma no mínimo compartilhada, as mulheres continuam sendo as principais responsáveis pelo cuidado com crianças pequenas (Bruschini e Lombardi, 2001).

Esse quadro aponta para uma realidade na qual a desnaturalização do papel tradicionalmente feminino de cuidadora dos demais membros da família é um processo mais lento que a aceitação de que o provimento do sustento do lar não é um atributo exclusivo dos homens. Ou seja, é aceito socialmente de modo mais amplo que uma mulher trabalhe fora do que a divisão das tarefas domésticas entre ela e seu cônjuge. Oliveira (2005) destaca um elemento importante no discurso de homens de nível universitário entrevistados em sua pesquisa: a expectativa de uma companheira que trabalhe fora e compartilhe as despesas do domicílio. Para estes segmentos, o trabalho femino não apenas seria aceito mas desejável, podendo se converter em uma dimensão importante no processo de escolha da parceira.

Neste contexto, partimos do pressuposto de que o trabalho em tempo parcial - por permitir às mulheres acomodar seu duplo papel - acentua as disparidades existentes na repartição do trabalho doméstico no interior do casal. Foi este historicamente o modelo que assegurou às mulheres um investimento simultâneo e balanceado entre trabalho produtivo e reprodutivo, enquanto os homens continuaram mais centrados no primeiro. Este tipo de modelo instaura uma divisão sexual do trabalho atenuada, onde as mulheres continuam cumprindo as atividades de cuidadoras, contribuem nas despesas da casa, mas não disputam com os homens o lugar que, no mercado de trabalho, continuaria sendo por excelência masculino. Nos anos 1970 este arranjo parece ter sido amplamente acionado por casais mais escolarizados, em um contexto marcado pela concentração feminina em atividades ligadas ao magistério ou outros postos de trabalhos com horários mais flexíveis.

Bruschini e Lombardi (1999) indicam uma mudança deste quadro com a expansão da presença feminina em carreiras universitárias de prestígio. A autora destaca o processo de entrada das mulheres em redutos tradicionalmente masculinos como fruto de uma convergência de fatores. Por um lado, em função da intensa transformação cultural nos anos 1970, que impulsionou as mulheres para as universidades. O processo de expansão das vagas dos cursos universitários que caracteriza o período é destacado por alguns autores como resposta a uma demanda eminentemente das mulheres. ${ }^{3}$ Por outro, as transformações pelas quais passaram as profissões, em direção à especialização e ao assalariamento, em detrimento da antiga autonomia profissional. Essa mudança teria repercutido negativamente no nível de prestígio atribuído a esses profissionais, o que teria aberto outras possibilidades para a inserção feminina além dos espaços tradicionalmente ocupados por elas como o magistério e a enfermagem. 
Os resultados a que chegamos (Guedes, 2007) vão nesta direção, pois constatamos um crescente peso da população feminina no grupo de formados em todas as carreiras universitárias. ${ }^{4}$ Este fenômeno é particularmente relevante para a estruturação de novas identidades de gênero se olhamos as carreiras de maior prestígio. Evidentemente esta tendência sugere a conformação de representações do feminino mais voltadas para o mundo do trabalho e para o tipo de profissional altamente qualificado que passa a ser visado pelo mercado e pelas empresas a partir do processo de globalização e reestruturação produtiva assistido no contexto brasileiro a partir dos anos 1990.

Wainerman (2007) mostra que esse processo também vem acontecendo na Argentina, onde a incorporação feminina aos níveis mais altos de educação constituiria um fenômeno explosivo das últimas décadas. A feminização da matrícula no cenário argentino teria ocorrido mediante um avanço lento mas contínuo sobre carreiras que, no passado, eram privativas dos homens. Do mesmo modo que em outros países, como o Brasil, essa tendência é concomitante à entrada das mulheres no mercado de trabalho.

A autora, no entanto, apresenta uma visão crítica ao salientar o caráter contraditório da inserção feminina em um momento de crise econômica e flexibilização das regras nas quais esta mão de obra se insere. Segundo ela, a incorporação de mais mulheres à atividade laboral não poderia ser interpretada simples e exclusivamente como indicador de modernização, desenvolvimento ou crescimento, como se entendia nos anos 1970, quando a participação laboral se traduzia em esperanças de mudança na condição feminina. No contexto atual, o processo de intensificação do ingresso das mulheres no mercado de trabalho também se deve ao fato dessa ser uma mão de obra mais barata e que trabalha em condições mais precárias.

Em relação a estes recentes processos históricos, Hirata (2001) destaca como consequência dessa inserção laboral fragilizada uma diversificação das funções desempenhadas pelas mulheres, configurando um quadro de bipolarização das trabalhadoras brasileiras: em um extremo, profissionais altamente qualificadas, com salários relativamente elevados no conjunto da mão de obra feminina e, no outro extremo, trabalhadoras ditas de 'baixa qualificação', com baixos salários e tarefas sem reconhecimento nem valorização social. Este tipo de distribuição e o processo de valorização e maiores salários dos trabalhadores que se encontram no topo da pirâmide é uma dimensão que caracteriza tanto a mão de obra feminina quanto a masculina, como revela a própria autora. No entanto, é importante salientar que enquanto esse processo é recente entre as mulheres, é antigo entre os trabalhadores homens. Este padrão comum reflete o quanto o comportamento e as trajetórias laborais de homens e mulheres deste segmento altamente escolarizado vem se aproximando, o que contrasta com a realidade assistida nos anos 1970. 
Leone e Baltar (2006) reforçam essa perspectiva ao discutirem dados comparativos sobre a mão de obra feminina e masculina no mercado de trabalho metropolitano nos anos 1990, provenientes das PNADs de 1992 e 2002. Assim como Hirata, os autores apontam que o período marca uma melhora do rendimento dos trabalhadores com nível universitário e daqueles com até oito anos de estudo. No entanto, é destacado também o fato de que a distância salarial entre aqueles e estes aumentou no período. Ou seja, mais uma vez o processo de avanço das mulheres pertencentes ao segmento mais escolarizado rumo aos postos mais bem remunerados no mercado é ressaltado como elemento importante da dinâmica laboral dos anos 1990.

No segmento de trabalhadores com nível universitário, os autores mostram que as mulheres passam a ser maioria da mão de obra (51\%). Apesar da maior participação feminina, ressaltam que é justamente neste grupo que as diferenças salariais seriam mais expressivas. Finalmente, apontam para a existência de uma variedade de ocupações de nível superior oferecidas às mulheres, embora essas ocupações não atinjam remunerações tão altas quanto as masculinas de mesmo nível educacional. Ao longo do tempo, essas diferenças mantêm-se elevadas, apesar de terem apresentado leve tendência de queda.

Vale destacar que esse maior diferencial salarial por sexo no estrato que recebe os maiores rendimentos já seria esperado. É neste segmento que há maior diversidade de especializações e uma progressão ao longo da carreira, com o teto salarial mais variável. Os ocupantes dos cargos mais altos na hierarquia são geralmente trabalhadores homens, cujos salários são substancialmente mais elevados que os dos demais trabalhadores de nível universitário. Em contrapartida, entre os trabalhadores da base da pirâmide salarial há um conjunto de salários uniformemente baixos, independente do sexo do trabalhador.

No tocante aos processos que marcam os anos 1990, dois são particularmente relevantes quando se analisa o mercado de trabalho brasileiro de uma perspectiva de gênero: a terceirização dos empregos e a estagnação do setor formal. Ambas as tendências estariam articuladas ao fechamento de postos de trabalho no setor industrial da economia brasileira no início da década em função da intensificação do processo de reestruturação produtiva. Marques (2006) mostra que, neste período, o emprego formal feminino cresceu, compensando a queda de empregos masculinos, o que acabou resultando em um quadro geral de estagnação. Essa melhora da presença feminina teria sido ocasionada, particularmente, pela intensa expansão do setor de serviços, tradicional reduto da mão de obra feminina.

Utilizando-se de dados da Rais (Relação Anual de Informações Sociais) de 1996 e 2000 para o setor de serviços, o autor destaca que em três subsetores o número de mulheres ocupadas supera o de homens: no setor administração 
pública, defesa e seguridade social; no setor ensino; e no setor saúde e serviços sociais. Em relação ao quadro geral do setor de serviços, Marques pontua que as mulheres possuem escolaridade igual ou superior à dos homens em todos os subsetores, característica relevante tendo em vista que, ao longo do período, a escolaridade média cresceu. No entanto, as mulheres auferem rendimentos médios menores que os masculinos em todos eles. Esse quadro sugere que mesmo em nichos em franca expansão e com acentuada presença feminina as desigualdades salariais por sexo, particularmente nos segmentos mais escolarizados da mão de obra, continuam constituindo-se como uma questão central a despontar nas pesquisas no campo do mercado de trabalho no Brasil.

Todaro et al. (2001) apontam elementos importantes na direção das explicações para esta desigualdade salarial no caso do Chile. As autoras partem da ideia de que a percepção de empresários e executivos sobre o desempenho laboral de homens e mulheres teria um efeito significativo em suas possibilidades de acesso ao emprego e em suas condições de trabalho. Com base em pesquisa do contexto chileno com 203 empresas e 17 entrevistas em profundidade, as autoras concluem que a opinião favorável ou desfavorável dos empresários a respeito do desempenho de mulheres e homens obedece fundamentalmente a uma definição prévia das características das distintas ocupações. No entanto, essa classificação teria pouco a ver com os elementos técnicos ou organizativos das ocupações, estando mais articulada ao caráter masculino ou feminino socialmente atribuído a elas. Isso refletiria a predominância de uma ordem de gênero como critério de caracterização e classificação das empresas e das ocupações como mais ou menos adequadas para homens e mulheres, definindo, com isso, verdadeiros territórios femininos e masculinos no mundo do trabalho.

Guimarães traça um amplo panorama das desigualdades de sexo e cor no mercado de trabalho brasileiro através de dados das PNADs de 1989 e 1999. Empregando o salário dos homens brancos como referência, a autora cria um modelo no qual são decompostos os determinantes das diferenças entre os rendimentos dos grupos de sexo e cor na população ativa. Os possíveis fatores explicativos da desigualdade de rendimentos utilizados por Guimarães em seu modelo são: qualificação, inserção formal, inserção regional, inserção ocupacional. Uma vez isoladas cada uma destas componentes, a persistente variação do salário/hora seria analisada como discriminação. No caso da população negra, tanto homens quanto mulheres, a menor qualificação desta mão de obra parece ser o principal fator que os separa dos homens brancos em termos salariais, já que uma vez isolado este fator o diferencial salarial desaparece. $\mathrm{O}$ dado mais interessante trazido pela autora é que, entre as mulheres brancas, o peso líquido da discriminação é o maior. Isso porque esse grupo dispõe de todos os demais ativos que propiciariam a 
igualdade em face dos rendimentos dos homens brancos, exibindo, além do mais, escolaridade significativamente mais elevada que a masculina.

Desse modo, Guimarães (2001) acaba por concluir que a única e significativa desvantagem na competição por rendimentos no grupo de mulheres brancas estaria inscrita no corpo, e não preponderantemente em desigualdades de origem social mais ampla. Sua condição de sexo as desqualificaria na disputa por melhores salários.

\section{As evidências de aproximação dos padrões de inserção feminino e masculino}

Grande parte das limitações em termos de comparabilidade da população masculina e feminina de nível universitário nos censos de 1970 e 2000, principal fonte de dados com as quais trabalhamos, diz respeito à composição etária da população em questão nos dois momentos históricos. Enquanto em 1970 as mulheres deste estrato de escolaridade estavam concentradas nos primeiros grupos etários, particularmente o de 20 a 29 anos, no Censo de 2000 esta população distribui-se mais ao longo de todas as idades. Esse diferencial reflete o processo de intensa entrada feminina nos cursos universitários no final dos anos 1960 e início dos 1970, quando a ampla maioria das mulheres que compunham o grupo eram jovens recém-formadas. Passados trinta anos, os egressos dos cursos superiores distribuem-se menos concentradamente nas idades, por se tratar de um fenômeno iniciado décadas antes.

Gráfico 1

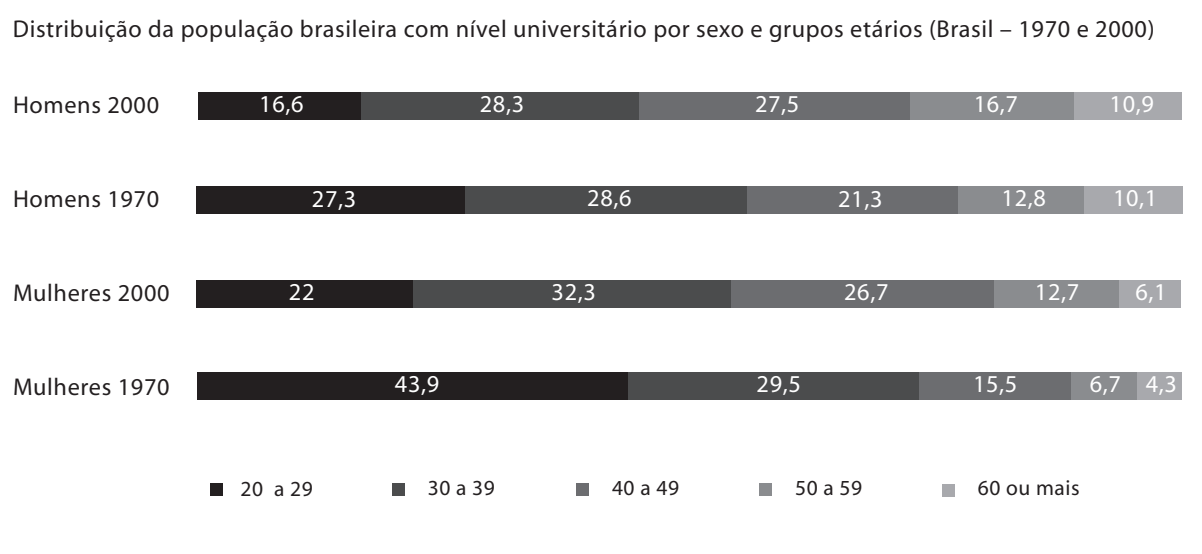

Fonte: Censos demográficos de 1970 e 2000, IBGE.

Nota: Dados trabalhados pelo autor. 
Como mostra o Gráfico 1, a população masculina em 1970 se encontrava mais equanimemente distribuída pelos grupos etários do que a feminina. Do ponto de vista do mercado de trabalho, a principal implicação é que grande parte deste contingente populacional não se encontra em início de carreira, como ocorre com as mulheres. Por esta razão, os homens apresentam em 1970 melhores condições de inserção e situação laboral. Não se quer aqui defender a idéia de que apenas a concentração feminina nos grupos etários mais jovens explica o grande diferencial salarial por sexo encontrado na população de nível universitário em 1970. No entanto, essa distribuição diferenciada ao longo dos grupos etários necessariamente tem que ser levada em conta nas análises sobre o tema.

$\mathrm{O}$ fato de a grande maioria das mulheres que chegaram a concluir um curso universitário naquele período estar no início da vida adulta e serem, portanto, recém-formadas cria um viés do ponto de vista das variáveis relativas ao mundo do trabalho. Apesar de reconhecermos essa limitação, optamos por não controlar as variáveis analisadas a seguir através da idade em função da ampla gama de respostas, que dificultam tanto a visualização de um perfil social claro quanto põem em xeque a validade das expansões das distribuições amostrais para o universo da população em questão. Na medida do possível, mencionaremos o sentido das limitações dos dados desse modo estruturados nas análises a seguir.

Em relação apenas à população de nível universitário empregada, tanto no Censo de 1970 quanto no Censo de 2000, busca-se evidenciar os principais avanços das mulheres no tipo de inserção laboral que conquistaram, lançando mão das variáveis 'posição na ocupação', 'horas semanalmente trabalhadas' e 'classes de rendimento em salários mínimos'. Finalmente, analisa-se a distribuição dos trabalhadores de nível universitário por sexo nos grandes grupos de ocupação da atividade principal em 2000, o que permite visualizar alguns nichos tipicamente femininos e masculinos no mercado de trabalho.

Como apontado anteriormente, o mercado de trabalho brasileiro assistiu a intensas modificações no cenário econômico ao longo do período que temos como foco. Grande parte destas transformações está articulada à expansão do modelo neoliberal da economia, cujas principais características são a flexibilização das relações de trabalho, o desmantelamento do Estado de 'bem-estar social' e o crescimento do chamado setor informal. Este processo estruturou um cenário no mundo do trabalho bastante diferente daquele encontrado em 1970.

Estas mudanças se refletem na própria forma como o IBGE captou a informação relativa à 'posição na ocupação' dos trabalhadores brasileiros. Enquanto no Censo de 1970 a preocupação estava mais ligada à esfera 
(pública ou privada) da ocupação e as opções de resposta eram poucas (seis), no Censo de 2000 a questão da carteira de trabalho assinada passa a ser crucial e a maior opção de respostas (nove) reflete a multiplicidade de situações laborais que o levantamento passa a considerar.

Gráfico 2

Distribuição da população brasileira com nível universitário segundo a posição na ocupação por sexo - Censo de 1970

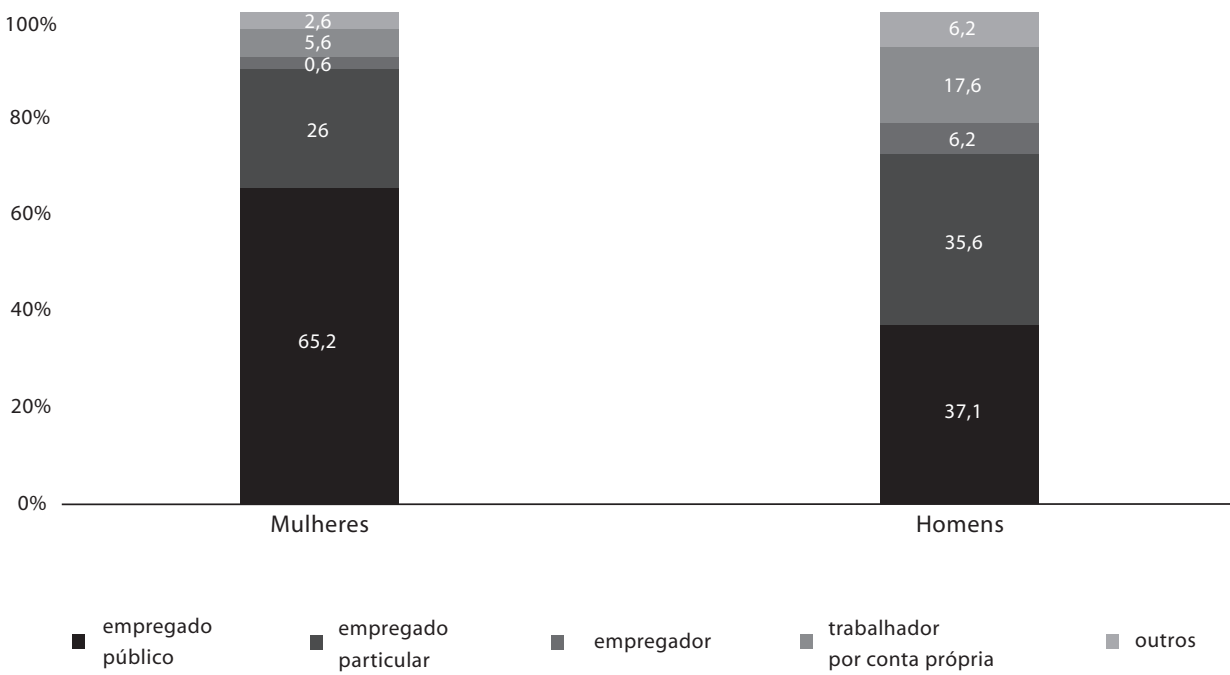

Fonte: Censo demográfico de 1970, IBGE.

Nota: Dados trabalhados pelo autor.

O Gráfico 2 mostra uma situação bastante diferenciada entre trabalhadores homens e mulheres. No que diz respeito à posição na ocupação em 1970, por se tratar de populações muito desiguais em termos dos volumes absolutos (para cada três homens de nível universitário havia uma mulher), a cautela recomenda trabalhar apenas as diferenciações internas a cada grupo. A questão de o contingente feminino estar bastante concentrado na categoria 'empregado público' reflete o peso de categorias profissionais ligadas à chamada economia do cuidado (particularmente professoras de escolas públicas), setor em larga medida subsidiado pelo estado. O peso das professoras neste segmento de trabalhadores evidencia a difusão de um modelo bastante comum 
no período: professoras primárias que fizeram o curso Normal no ensino secundário e ingressam nas universidades para se diplomar em carreiras que as mantêm no nicho educacional, ainda que enquadradas em séries mais avançadas do ensino, respondendo por disciplinas que exigem um conhecimento mais especializado do professor.

A população masculina, por sua vez, encontra-se mais bem distribuída entre todas as alternativas de enquadramento e apresenta um percentual relativo consideravelmente mais alto que o feminino nas posições de 'trabalhador por conta própria' e 'empregador'. Note-se que neste grupo masculino de nível universitário enquanto $6,2 \%$ dos homens estão na categoria 'empregador' - a de maior pretígio - a proporção de mulheres é apenas 0,4\%. Chamaríamos atenção também para o fato de que o significado de ser 'trabalhador por conta própria' em 1970 era certamente diferente do que será trinta anos depois ou mesmo atualmente. O encolhimento do setor formal de empregos cria uma realidade na qual este tipo de inserção nem sempre resulta de uma opção feita pelo profissional, situação provavelmente corrente naquele contexto temporal.

O Gráfico 3, a seguir, apresenta as informações relativas ao Censo de 2000. A categoria 'outros' agrega as seguintes opções de resposta: trabalhador doméstico com carteira de trabalho assinada, trabalhador doméstico sem carteira de trabalho assinada, aprendiz ou estagiário sem remuneração, não remunerado em ajuda a membro do domicílio e trabalhador na produção para o próprio consumo. Apesar da dimensão investigada ser a mesma, como já mencionado, as categorias de enquadramento da posição na ocupação no Censo de 2000 não são compatíveis com as utilizadas no de 1970. Uma questão a ser destacada é que, além desta mudança nas categorias que aparecem como possíveis respostas, difere também a forma como a pergunta é formulada no Censo de 2000, passando a ser: "Neste trabalho era...". Em 1970 a pergunta era qual é a 'posição na ocupação'. Em que pese estas dificuldades de comparabilidade, o que mais chama atenção em 2000 é que a distribuição dos trabalhadores homens e mulheres é muito semelhante. Esta semelhança não observada em 1970 sugere uma possível aproximação dos padrões de inserção feminino e masculino no mercado de trabalho em 2000. 
Gráfico 3

Distribuição da população brasileira com nível universitário segundo a posição na ocupação por sexo - Censo de 2000

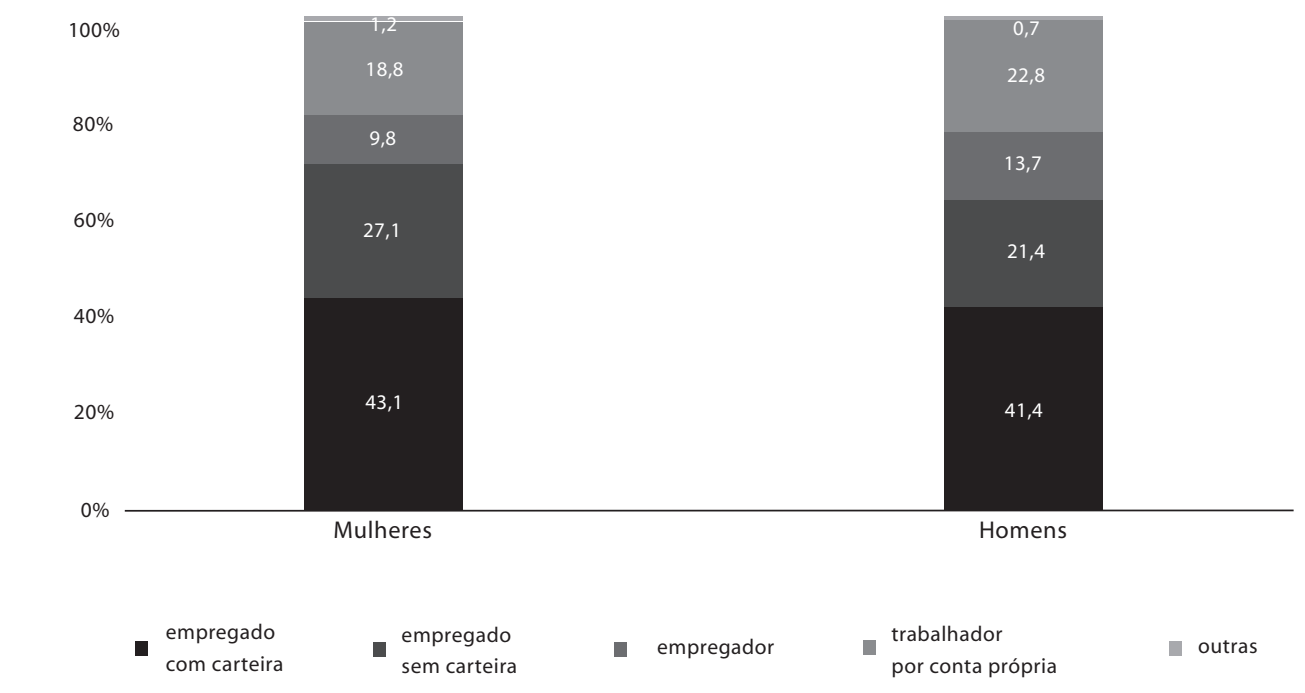

Fonte: Censo demográfico de 2000, IBGE.

Nota: Dados trabalhados pelo autor.

A análise da distribuição feminina segundo o lugar na ocupação no Censo de 2000 revela uma tendência de maior heterogeneidade do contingente de mulheres trabalhadoras. Por um lado, a categoria 'empregador', de maior prestígio social, abarca quase $10 \%$ deste segemento de mulheres. Em que pesem os problemas de comparabilidade entre os censos, o trabalho feminino como empregador adquire em 2000 maior expressão do que em 1970, quando apenas 0,4\% das mulheres se enquadravam nesta categoria. Por outro lado, categorias bastante desvalorizadas socialmente como a de 'empregado(a) doméstico(a)' (agregada a outras categorias no grupo 'outros'5) não apresentam, na população de nível universitário, nenhuma participação masculina enquanto que no contingente feminino de mesma escolaridade $0,1 \%$ se encontra nesta situação com carteira de trabalho assinada e $0,2 \%$ sem sequer este direito trabalhista. Apesar deste contingente não ser tão expressivo em termos quantitativos, sua carga simbólica reflete o quanto é mais aceito e vivenciado na prática, entre as mulheres pertencentes a este segmento altamente qualificado, uma inserção mais precarizada, que não reflete nem considera o tipo de investimento feito no campo educacional por essas trabalhadoras. Esta questão também se verifica no maior peso da categoria 'sem carteira assinada' na população feminina. 
Esta tendência de maior diferenciação interna do contingente de trabalhadoras mulheres também se reflete na variável rendimento em salários mínimos. O balanço dos últimos trinta anos, como mostra a Tabela 1,6 revela uma persistência de concentração feminina nos grupos mais malremunerados concomitantemente a um crescimento expressivo do grupo mais bem remunerado. Estes dados vão de encontro ao que sugere a literatura discutida acerca das tendências a partir dos anos 1990 para esta mão de obra mais qualificada.

Tabela 1

Distribuição da população brasileira de nível universitário por sexo e segundo estratos de rendimento em salários mínimos - 1970 e 2000

Mulheres 1970 Mulheres 2000 Homens 1970 Homens 2000

$\begin{array}{lcccc}\text { Até } 5 \text { salários mínimos } & 64,9 & 32,1 & 23,5 & 14,1 \\ \text { de } 5 \text { a } 10 \text { salários mínimos } & 27,2 & 35,8 & 30 & 25,2 \\ \text { de } 10 \text { a } 15 \text { salários mínimos } & 5,8 & 13,4 & 22,2 & 15,1 \\ \text { de } 15 \text { a } 20 \text { salários mínimos } & 1,4 & 8,6 & 12,2 & 14,9 \\ \text { de } 20 \text { a } 30 \text { salários mínimos } & 0,6 & 5,2 & 9,2 & 11,8 \\ \text { mais de } 30 \text { salários mínimos } & 0,1 & 4,8 & 2,7 & 18,9 \\ & & & & 100\end{array}$

Fonte: Censos demográficos de 1970 e 2000, IBGE.

Nota: Dados trabalhados pelo autor.

As principais diferenciações de um censo para outro reveladas pela tabela são, no caso das mulheres, a desconcentração da população de trabalhadoras apenas no estrato mais mal remunerado (até cinco salários mínimos), passando a concentrar-se também no segundo estrato (que chega a ser majoritário em 2000) e a distribuir-se mais uniformemente nos demais. Essa melhora é a mudança mais expressiva apontada pela tabela. No entanto, esse diferencial em relação ao Censo de 1970 pode refletir o peso das coortes mais velhas em 2000, quando uma parcela mais expressiva de mulheres já se encontra em etapas mais avançadas da carreira e, por esta razão, melhoram seu rendimento. 
No contingente masculino de trabalhadores também se observa uma desconcentração. Contudo, no caso dos homens, a distribuição no Censo de 2000 equaliza as categorias de rendimento, tornando muito semelhantes todos os estratos. Ou seja, a diferenciação interna deste grupo de trabalhadores é menor que aquela observada no contingente feminino na mesma situação. Essa equalização e o peso importante do melhor estrato de rendimento evidenciam o quanto a distribuição interna masculina é melhor que a feminina no que diz respeito aos rendimentos do trabalho.

Como mostra a literatura discutida no início deste capítulo, a brecha salarial entre homens e mulheres de nível universitário diminui muito pouco neste período recente. Esta conclusão é visível nas distribuições contidas na tabela, pois ainda que a situação salarial das mulheres melhore, o avanço salarial no contingente masculino é mais intenso. Ou seja, todos os trabalhadores com nível universitário passaram a ganhar mais ao longo deste período, sendo o crescimento do grupo mais bem remunerado (mais de 30 salários mínimos) mais intenso no caso do contingente masculino.

Um aspecto importante a ser salientado é que há uma necessidade de relativização da informação expressa no gráfico: o aumento do rendimento da população de nível universitário em salários mínimos pode não significar diretamente uma melhora em seu padrão de vida. Isso porque o poder de compra do salário mínimo mudou significativamente nos trinta anos que abarcam nossa pesquisa. Silva et al. (2006) revelam que o comportamento do salário mínimo mostrou bastante variabilidade entre 1970 e 2000 . A partir do ano de 1995, o que se percebe é uma trajetória ascendente, ainda que esta não se equipare, em termos de valores, àqueles atingidos especialmente na primeira metade da década de 1980. Segundo as autoras, os valores atingidos pelo salário mínimo para a década de 1970 não foram retomados até o fim do período analisado. Ou seja, teria havido ao longo do período uma perda da classe trabalhadora em termos de capacidade de compra.

Em relação à variável 'horas semanais trabalhadas', existe maior semelhança entre homens e mulheres. Em linhas gerais, ambos os contingentes de trabalhadores apresentam ampla maioria concentrada no estrato que representa o chamado trabalho full time, correspondente a pelo menos 40 horas por semana. Essa tendência se acentua de um censo para o outro no caso das mulheres e permanece bastante semelhante no caso dos homens. Os trabalhadores masculinos de nível universitário já estavam mais concentrados neste estrato em 1970, enquanto as mulheres se aproximam da distribuição masculina ao longo do período, como mostra o Gráfico 4. 


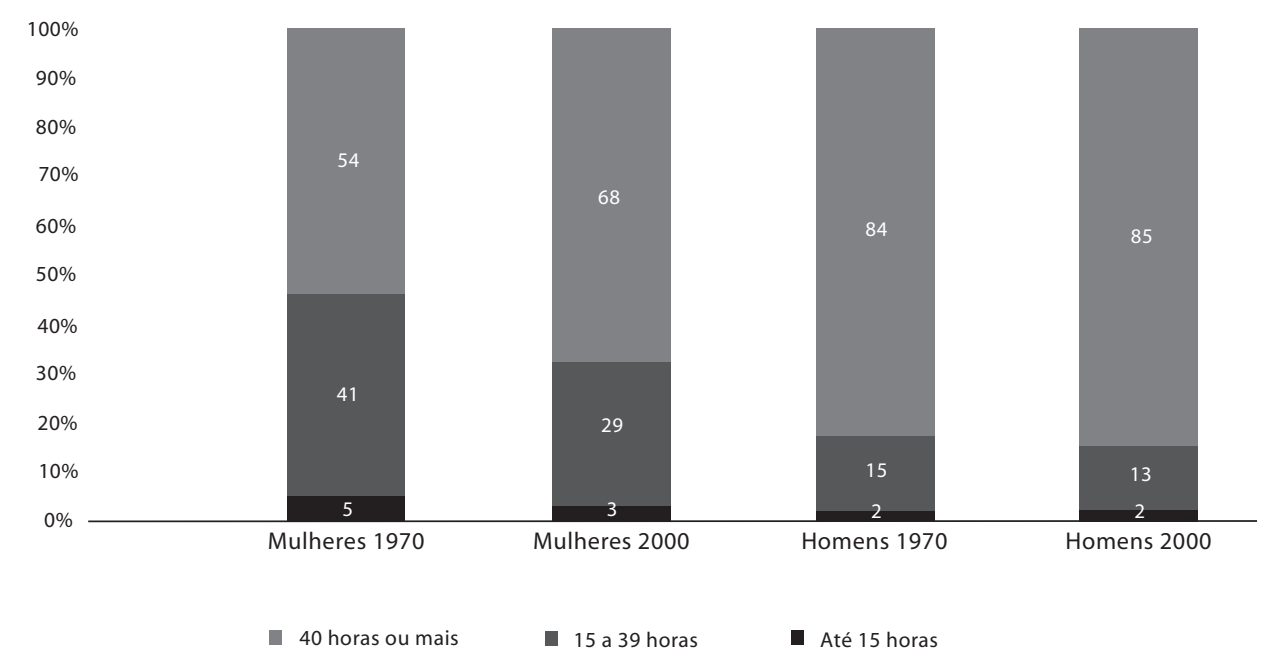

Fonte: Censos demográficos de 1970 e 2000, IBGE.

Nota: Dados trabalhados pelo autor.

De fato, as mulheres de nível universitário apresentam um quadro em 1970 onde o trabalho em tempo integral já representava a maioria. Contudo, nesta época o peso das trabalhadoras em tempo parcial também é expressivo, o que não ocorria nem ocorre com os homens. A queda na proporção de mulheres em tempo parcial e daquelas que trabalham apenas até 15 horas semanais no Censo de 2000 mostra que este contingente vem se aproximando cada vez mais do padrão masculino, no que tange ao tempo despendido com trabalho voltado para o mercado. Os homens, por outro lado, por já apresentarem em 1970 uma distribuição muito concentrada no estrato de mais horas semanais trabalhadas, quase não modificam sua composição em 2000, evidenciando nesta data um ligeiro aumento do estrato que mais trabalha.

A literatura mostra que, em relação a outros estratos educacionais, as mulheres de nível universitário são as que estão mais inseridas no mercado de trabalho (taxas de participação) e também as que dedicam maior tempo ao chamado trabalho produtivo ou voltado para o mercado (Araújo e Scalon, 2005). Diante disso, a questão posta para os estudos de gênero seria como se comportam os homens pertencentes a este estrato educacional em relação ao trabalho reprodutivo no interior das famílias. Ou seja, se a nova realidade de casais de provedores de fato impulsiona uma reacomodação dos papéis tradicionais também no universo doméstico da vida social. 
Com a introdução da pergunta sobre uso do tempo com tarefas domésticas na PNAD a partir de 2001, este universo passa a poder ser desvendado e a variável escolaridade mais uma vez aparece como dimensão fundamental para a compreensão de expressivos diferenciais na população brasileira. Com base em tabulações da referida pesquisa, Dedecca (2004) aponta que as mulheres inseridas no mercado de trabalho e que realizam afazeres domésticos tendem a auferir uma remuneração menor que aquelas que não realizam. O dado interessante é que essa diferenciação de remuneração não é encontrada entre os homens. Outra dimensão importante destacada pelo o autor é que, em todos os estratos educacionais, as mulheres despendem mais horas com o trabalho doméstico que os homens.

Em trabalho mais recente, Dedecca et al. (2008) afirmam que entre as mulheres há uma relação inversa entre nível de escolaridade e jornada de trabalho destinada à reprodução social. Segundo ele, mulheres com baixa escolaridade tendem a ter jornadas domésticas em média $75 \%$ superiores às das mulheres com nível universitário completo. No entanto, é destacado que a melhor inserção ocupacional amenizaria a discriminação com relação à mulher, mas não permitiria superar sua situação em termos de jornada de trabalho para a reprodução. Isso não apenas porque elas continuariam despendendo um volume ponderável de horas com este objetivo, mas também porque os homens em mesma situação não ampliam suas responsabilidades nas atividades de reprodução social da família.

Uma outra dimensão fundamental a ser analisada é como se distribuem as mulheres e homens de nível universitário entre as ocupações, uma vez que a intensa expansão do contingente de indivíduos com este nível educacional, a partir dos anos 1990, criaria um excedente de mão de obra qualificada que, possivelmente, não estaria inserida na área à qual se dedicou no curso de graduação. A Tabela 2 mostra esta distribuição no Censo demográfico de 2000.7

Tabela 2

Distribuição da população de nível universitário inserida no mercado de trabalho por sexo e segundo grandes grupos de ocupação no trabalho principal - Brasil 2000

\begin{tabular}{lcc}
\hline & Homens & Mulheres \\
Membros superiores do poder público, dirigentes de & & \\
$\quad$ organizações de interesse público e de empresas e gerentes & 19,32 & 10,94 \\
Profissionais das ciências e artes & 45,97 & 52,75 \\
Técnicos de nível médio & 12,82 & 14,93 \\
Trabalhadores de serviços administrativos & 7,01 & 13,27 \\
Trabalhadores dos serviços, vendedores do comércio & & 5,18 \\
$\quad$ em lojas e mercados & 5,86 & 0,25 \\
Trabalhadores agropecuários, florestais, de caça e pesca & 1,66 & continua >
\end{tabular}




\begin{tabular}{lcc}
\hline & Homens & Mulheres \\
& & 0,99 \\
Trabalhadores da produção de bens e serviços industriais & 2,90 & 0,03 \\
Trabalhadores de reparação e manutenção & 0,54 & 0,15 \\
Membros das forças armadas, policiais e bombeiros militares & 1,70 & 1,51 \\
Ocupações mal-especificadas & 2,22 & 100 \\
& & 100 \\
\hline
\end{tabular}

Fonte: Censos demográficos de 1970 e 2000, IBGE.

Nota: Dados trabalhados pelo autor.

Os dados mostram que o principal diferencial de peso relativo - que acaba se refletindo nas demais categorias - é a maior concentração masculina na categoria "membros superiores do poder público, dirigentes de organizações de interesse público e de empresas e gerentes". O fato de esta ser uma categoria profissional que reflete prestígio social e está associada a maiores salários poderia explicar, em parte, os diferencias salariais encontrados entre homens e mulheres tratados acima. Em contrapartida, as mulheres encontram-se mais concentradas nas categorias 'profissionais de ciências e artes'. Esse quadro sugere que o nível educacional superior não se converta tão diretamente em melhores postos de trabalho quando comparamos a população feminina à masculina.

O balanço destas quatro variáveis analisadas reflete um quadro de clara aproximação feminina em relação ao padrão masculino de participação no mercado de trabalho. Tanto a variável 'lugar na ocupação' quanto a 'número de horas semanais trabalhadas' já apresentam em 2000 uma distribuição bastante semelhante entre homens e mulheres. As principais permanências são observadas nas variáveis 'renda estratificada em salários mínimos' e 'tipo de ocupação'. Apesar do crescente peso da mão de obra feminina nos estratos mais altos de renda, há ainda uma considerável distância em relação ao contingente masculino. Esse diferencial pode refletir a continuidade da concentração feminina em alguns nichos ocupacionais menos valorizados no mercado de trabalho.

\section{Considerações finais}

As diversas dinâmicas observadas no tipo de inserção dos trabalhadores brasileiros a partir do recorte educacional vêm se mostrando um campo fértil para as análises de gênero. Isso porque o investimento das mulheres na 
escolarização consolida valores e identidades menos orientados para o mundo doméstico, o que intervém diretamente nas dinâmicas observadas. A comparação entre distintos momentos históricos, todavia, mostra que o processo de inserção das mulheres mais escolarizadas no mercado de trabalho é marcado por rupturas, continuidades e uma crescente heterogeneização ao longo do tempo.

O que mais chama atenção nos dados analisados é que, apesar do investimento em termos de qualificação e tempo destinado à esfera produtiva serem bastante próximos entre homens e mulheres de nível universitário, os tipos de ocupação ainda fazem com que a renda masculina responda provavelmente por uma parcela maior do provimento das famílias. Esse quadro mostra que a idéia de uma 'divisão sexual do trabalho atenuada' já não seria muito aplicável à realidade dos anos 1970, quando a maioria das trabalhadoras deste segmento já estava inserida em tempo integral. Em todas as variáveis analisadas, assistimos à expansão de um modelo de trabalhadora cuja renda é fundamental nos provimentos familiares. Isso sugere um lugar cada vez mais central do mundo do trabalho e dos planos de progressão nas carreiras nas escolhas das mulheres.

Desde uma perspectiva mais ampla é difícil afirmar se essa tendência reflete pressões em relação à cultura de consumo das camadas médias e altas da sociedade brasileira ou se apontam para uma crescente lógica feminina que reconhece o campo do trabalho como um locus fundamental de realização e afirmação da identidade. Possivelmente ambos. O interessante a ser ressaltado na presente análise é que as escolhas ou constrangimentos que permeiam o tipo de ocupação que homens e mulheres exercem é de ordem mais simbólica que os constrangimentos concretos que historicamente alijaram as mulheres do espaço público.

\section{Nota do Editor}

Este artigo é parte do segundo capítulo da tese de doutorado $\mathrm{Na}$ medida do (im)possivel: família e trabalho entre as mulheres de nivel universitário, defendida em fevereiro de 2009 na Universidade Estadual de Campinas (Unicamp). A pesquisa foi financiada pelo CNPq. 


\section{Notas}

1 Vice-coordenadora do GT População e Gênero da Associação Brasileira de Estudos Populacionais (Abep); pesquisadora e professora da Universidade Estadual do Rio de Janeiro (Uerj), Rio de Janeiro, Brasil. Doutora em Demografia pela Universidade Estadual de Campinas (Unicamp). <moguedes@yahoo.com.br>

Correspondência: Rua Almirante Alexandrino, 2.946, apto. 101, Santa Teresa, Rio de Janeiro, Brasil, CEP 20241-261.

2 Selecionamos um grupo de cursos que refletisse algumas tendências apontadas no primeiro capítulo da dissertação a partir da comparação do contingente de formados por sexo entre os censos de 1970 e 2000: Letras e Serviço Social - intensificação da concentração feminina em carreiras desvalorizadas socialmente; Arquitetura e Odontologia - aumento da presença feminina que chega a representar maioria em carreiras de médio prestígio social; Medicina e Direito - crescimento expressivo da participação feminina sem contudo chegar à metade do contingente de formados em cursos de alto prestígio social; Engenharia - manutenção da baixa presença feminina (pequeno aumento no período) em carreiras tradicionalmente masculinas.

3 Barroso e Mello (1975) destacam um fator fundamental para a clara estratificação baseada no sexo existente na clientela potencial do ensino superior nos anos 1970: a altíssima proporção de mulheres no curso normal. No período estudado pelas autoras, 1955 a 1970, o percentual de mulheres concluintes do colegial que cursaram esta modalidade não variou, mantendo-se constantemente por volta de $63 \%$ do total de formandas. Esta opção tornava mais difícil seu acesso às universidades, uma vez que o conteúdo exigido nas provas de vestibular era quase por completo baseado em disciplinas lecionadas no chamado Ensino Secundário Científico e Ensino Secundário Clássico, cursados majoritariamente por meninos.

4 As mulheres chegam a ser maioria dos formados na ampla maioria de cursos universitários no Censo demográfico 2000.

5 As respostas agregadas na categoria 'outros', por apresentarem um peso relativo muito pequeno nas distribuições em questão, foram: 1 - Trabalhador doméstico com carteira de trabalho assinada; 2 - Trabalhador doméstico sem carteira de trabalho assinada; 3 - Aprendiz ou estagiário sem remuneração; 4 - Não remunerado em ajuda a membro do domicílio; 5 - Trabalhador na produção para o próprio consumo.

6 Os estratos de renda utilizados no gráfico foram estruturados a partir da divisão do que o entrevistado declarou como rendimento total de todos os trabalhos (Censo de 2000) e rendimento total (Censo de 1970) divididos pelo valor do salário mínimo no período em que as pesquisas foram a campo. $\mathrm{O}$ arranjo proposto agrega valores maiores que os utilizados nas tabulações do IBGE por tratar-se de um grupo social consideravelmente mais bem remunerado que a média da população brasileira.

7 Não realizamos o mesmo tipo de cruzamento com o Censo de 1970 porque os dados deste período não se encontram disponibilizados em grandes grupos. Como destaca Barreto (2008), ao todo a pesquisa categorizou 267 tipos de ocupações, organizadas a partir de uma ampla gama de classes de atividade da ocupação principal. 


\section{Referências}

ARAÚJO, Clara; SCALON, Celi. Percepções e atitudes de mulheres e homens sobre a conciliação entre família e trabalho pago no Brasil. In: - (Org.). Gênero, família e trabalho no Brasil. Rio de Janeiro: Editora FGV, 2005. p. 15-78

BARRETO, Arnaldo L. Interesses de Estado e as classificações de ocupação profissional nos censos demográficos brasileiros. In: ENCONTRO NACIONAL DE PLANEJAMENTO URBANO. Anais..., 2004. 10 p.

BARROSO, Carmem L. M.; MELLO, Guiomar N. O acesso da mulher ao ensino superior brasileiro. In: Cadernos de Pesquisa, São Paulo, n. 15, dez. 1975. p. 47-77.

BRUSCHINI, Cristina; LOMBARDI, Maria Rosa. Instruídas e trabalhadeiras: trabalho feminino no final do século XX. In: Cadernos Pagu, Campinas, n.17/18, 2001. p. 157-198.

Médicas, arquitetas, advogadas e engenheiras: mulheres em carreiras de prestígio. Revista Estudos Feministas, Florianópolis, v. 7, 1999. p. 9-24.

DEDECCA, Cláudio S.; RIBEIRO, Claudio; S. M.; HAJIME, Fernando. Ocupação e tempo de trabalho. In: ENCONTRO NACIONAL DE ESTUDOS POPULACIONAIS, 16., Caxambu. Anais... Belo Horizonte: Abep, 2008. 22 p.

Tempo, trabalho e gênero. In: COSTA et al. (Org.) Reconfiguração das Relações de Gênero no Trabalho. São Paulo: CUT Brasil, 2004. p. 21-52.

GUEDES, Moema de Castro. A presença feminina nos cursos universitários e nas pósgraduações: desconstruindo a idéia da universidade como espaço masculino. In: História, Ciências, Saúde-Manguinhos, Rio de Janeiro, v. 15, n. 3, jul.-set., 2008. p. 117- 132.

As mulheres de formação universitária: a reversão da desigualdade de gênero e seus reflexos no mercado de trabalho
(Brasil: 1970-2000). Dissertação (Mestrado em Estudos Populacionais e Pesquisas Sociais) - Rio de Janeiro: Escola Nacional de Ciências Estatísticas/IBGE, 2004.

GUIMARÃES, Nadya A. Os desafios da equidade: reestruturação e desigualdade de gênero e raça no Brasil. In: Cadernos Pagu, Campinas, n. 17/18, 2001. p. 237-266.

HIRATA, Helena. Globalização e divisão sexual do trabalho. In: Cadernos Pagu, Campinas, n. 17/18, 2001. p. 139-158.

LEONE, Eugênia T; BALTAR, Paulo. Mercado de trabalho metropolitano: gênero e diferenças de rendimento, 1992-2000. In: Gênero, Niterói, v. 6, n. 2-v. 7, n. 1, 2006. p. 37-58.

MARQUES, Osiris. As mulheres e os serviços formais: o que mudou na década de 1990? In: Gênero, Niterói , v. 6, n. 2-v. 7, n. 1, 2006. p. 59-78.

OLIVEIRA, Maria Coleta F. A. Tendências contemporâneas e a família como questão. In: SEMINÁRIO SOBRE FAMÍLIA E POLÍTICAS PÚBLICAS NO BRASIL, 2005, Belo Horizonte. Anais... Belo Horizonte: Abep, 2005. 20 p.

PERROT, Michelle. Minha história das mulheres. São Paulo: Contexto, 2007. 190 p.

SILVA, Roselaine N. B; OLIVEIRA, Ana L.P.; CAVILHÃO; Ieda M. Determinantes da formação do valor da força de trabalho: uma contribuição para o caso brasileiro referente ao período de 1985-2000. In: Revista Faz Ciência, Cascavel, n. 8, Unioeste, 2006. p. 149-182.

SOARES, Sergey; ISAKI, R. S. A participação feminina no mercado de trabalho. Seminários Dimac, Ipea, n. 127. 37 p.

TODARO, Rosalba; GODOY, Lorena; ABRAMO, Laís. Desempeño laboral de hombres y mujeres: opinan los empresarios. In Cadernos Pagu, n. 17/18, 2001. p. 197- 236. 
WAINERMAN, Catalina. Mujeres que trabajan. Hechos e ideas. In: Torrado, Susana (Org). Población y bienestar en la Argentina del primero al segundo Centenario: una historia social del siglo XX. Buenos Aires: Edhasa, 2007. p. 143- 182 .

Recebido em 18/02/2010

Aprovado em 08/03/2010 